\title{
Dossiê Temático Programa de Pós-Graduação em Psicologia da Universidade Federal do Rio Grande do Norte 20 anos: passado, presente e futuro da pesquisa e da pós-graduação em psicologia
}

\section{Editorial}

Years ago, in his test to become a full professor at the Federal University of Espírito Santo, Professor Paulo Menandro, with his usual enthusiasm, explained that when preparing a career history, we give the impression that everything was a carefully conceived plan followed to the letter. All of us know how divorced from reality this is; our trajectory is marked with changes in direction, spur of the moment decisions, and the ever present stumbling blocks.

The purpose of this preamble is to begin this story by saying that the creation of the Graduate Psychology Program at the Federal University of Rio Grande do Norte - PPgPsi-/UFRN, which is celebrating its $20^{\text {th }}$ anniversary in 2019, as incredible as it may seem, was born from a "plan"! A so-called plan, because it was a simple, vague idea that could never have foreseen what would be achieved in the ensuing years.

It is a well-known fact that the uneven wealth distribution in Brazil has an impact on virtually all sectors in the country. The regional imbalance is evident in the indicators of any area of activity. Obviously, this imbalance also includes science and education. Indicators provided by the respective ministries and associated institutions reveal the plain truth. In the late 1990s, this situation was even more dire, given the level of concentration in the more economically developed regions of the country.

This reality prompted us to devise a plan for certification in Psychology at UFRN. The Department of Psychology had very few full professors at the time. The excellent Psychobiology Graduate Program was operating in affiliation with the Department of Physiology/Bioscience Center, resulting from a program along the lines of the future Minter/ Dinter at the Federal University of São Paulo/UNIFESP (formerly the Paulista School of Medicine), under the visionary leadership of Professor Elisaldo Carlini.

In the mid-1990s, the Department of Psychology collaborated with the University of São Paulo, more specifically, the Department of Clinical Psychology, in a pre-Minter/Dinter teacher training initiative. Although its scope meant it was not the best alternative from a departmental qualification standpoint, this choice was understandable given the markedly clinical emphasis during those years. The agreement was signed and several of the professors who at one time belonged to the Psychology Graduate Program took part. Despite its specificity and difference from the Graduate Program that would be created, it was unquestionably part of the "plan". It is also important to underscore that a number of professors were involved in the qualification process at different institutions in Brazil and abroad.

The second part of this "plan" occurred by chance. The Applied Psychology Service (SEPA - initially Center for Applied Psychology), currently the school-clinic of the Psychology course, was celebrating its twentieth anniversary. At the behest of its director, João Carlos Argolo, an event was held to commemorate the occasion. The interventions were recorded and their transcriptions were going to be published, but never were. Significantly altered, they were eventually published in the first issue of the Psychology Studies journal (Natal, Brazil).

This initially unpretentious project ultimately became the first step in the creation of the journal. Naively, it must be admitted, we had no idea of the complexity involved in this undertaking. With the participation of Professor Márcio Capriglione and later, José Pinheiro, we launched the journal, today classified as A1 in the Qualis system, and one of the first areas to be included in the SciElo Library. Professor Pinheiro was the journal's editor for years, succeeded by Professora Isabel Fernandes de Oliveira, both of whom were undoubtedly decisive in consolidating the journal. However, the journal is a story for another time; I mention it here only to point out that it was part of the "plan". There is, however, a set of parallel related events that deserve to be highlighted here.

CAPES (Coordination for the Improvement of Higher Education Personnel) took the first steps toward creating the journal classification system (Qualis). The Representative (today called "Coordinator") of Psychology, Professor Lino de Macedo from the University of São Paulo, established and took part in a commission, which also included Professors 
Maria do Carmo Guedes, from the Pontifical Catholic University of São Paulo, José Lino Bueno, from the University of São Paulo, Ribeirão Preto Campus (and member of the Assessment Commission in the area), Sílvia Koller, from the Federal University of Rio Grande do Sul (then editor of the journal Psychology: Reflection and Criticism), and Cláudio Hutz, also from the Federal University of Rio Grande do Sul, and then president of the National Association for Graduate Research in Psychology (ANPEPP), who also played a key role in implementing Psychology in Qualis.

I mention this to emphasize that after the start of the journal, with no clear idea of how to edit a scientific publication, participation from the very beginning in the creation of the Qualis system was decisive in qualifying the Psychology Studies journal (Natal). Likewise, establishing parameters to evaluate the quality of publications played an important role for other journals in the area, but this is another matter, already discussed in the literature.

Finally, the third initiative was implementing the Graduate Psychology Program itself. In partnership with Professor José Pinheiro, we launched the project knowing that it would be important, given the conditions we faced at the time, to propose an initial stage (something like a "pilot") of the Program with the creation of a Specialization in Psychology course in which we could test some of the ideas proposed for the Program, such as methodology-based disciplines and research monographs, among others. The first course was given in 1996, coordinated by Professor Elza Dutra, then a doctoral student under an agreement with the University of São Paulo.

Having gained some experience in this field and with the administration's authorization to offer teaching positions (under university President José Ivonildo do Rêgo and Professor Zeneide Ferreira Alves, Director of the Center for Arts and Human Sciences), we prepared the proposal for creating the Program (with the important guidance of Professors Jairo Borges, from the University of Brasília and José Lino Bueno from the University of São Paulo, then members of the CAPES Assessment Commission).

Events from that point on are common knowledge. The Program was recommended by the area and the CTC (Technical-Scientific Council) of CAPES, receiving an initial score of 3 and at the first triennial assessment, a score of 4 (2001). The Program was awarded a score of 5 in 2004, which it has maintained until now (ratified in the triennial assessment of 2017).

This 20-year trajectory includes a number of years of the Social Psychology Integrated Graduate Program, in association with the Federal University of Paraíba (UFPB) Social Psychology Graduate Program. This experience, which involved only the Doctoral course, preceded the creation of this level in the two Programs. The initial version included Professors Leoncio Camino, Francisco Albuquerque, Mardonio Rique Dias and Valdiney Gouveia, from UFPB and José Pinheiro, Livia Borges, Martha Traverso-Yepez and myself, from UFRN. The Program, an initiative that preceded the creation of associated programs by CAPES, was very successful, maintaining a score of 5 throughout its existence.

After two decades, the impression left by both the Psychology Graduate Program and the Psychology Studies journal (and professor training; virtually all the professors in the department hold doctorates) is that the "plan" produced extremely positive results. The truth is that these initiatives were developed over time and with the help of many. The "plan" was much less a "strategic plan" than a goal that we dreamed about and embraced. This special edition of the Psychology Studies journal, which commemorates two decades of publishing, is a testimony to what was achieved during this period, and, in my opinion, completely justifies the high ratings received by the PPgPsi-UFRN and the Psychology Studies journal (Natal). All those who participated in this journey have every reason in the world to feel proud.

At first I was reluctant to accept the invitation to write this Editorial given that I have been so actively involved in this project and cannot evidently provide an unbiased report. This inside story certainly needs to be expanded with additional information, since it is a very personal account. I would like to close by apologizing to the people who played an important role in this process that I have not cited. My intention was not to present a detailed report, but only to describe the more general aspects. On behalf of all the individuals mentioned, I salute all those who participated in this "plan".

Natal, October 2018.

Oswaldo H. Yamamoto 